(C)American Psychological Association, 2016. This paper is not the copy of record and may not exactly replicate the authoritative document published in the APA journal. Please do not copy or cite without author's permission. The final article is available, upon publication, at: http://dx.doi.org/10.1037/spq0000191 


\section{Improving Approximate Number Sense Abilities in Preschoolers: PLUS games}

Jo Van Herwegen ${ }^{1}$, Hiwet Mariam Costa ${ }^{1,2}$, \& Maria Chiara Passolunghi ${ }^{2}$

${ }^{1}$ Department of Psychology, Kingston University London, Kingston-Upon-Thames, UK

${ }^{2}$ Department of Life Sciences, Psychology Unit, University of Trieste, Trieste, Italy

Correspondence concerning this article should be addressed to Jo Van Herwegen, Department of Psychology, Kingston University London, Kingston-Upon-Thames, KT1 2EE, e-mail: j.vanherwegen@kingston.ac.uk.

Acknowledgements

We would like to thank all the children and nurseries who took part in this study. We are also indebted to Angela Mullins, Zina Malliarou, Tamsin Polson, Sanaz EntessariTafati, Karman Shing, Zuber Mohammed, Tayana Soukup, and Ania Stopa for their help with the data collection and provision of the PLUS game training programme.

Improving Approximate Number Sense Abilities in Preschoolers: PLUS Games 


\begin{abstract}
Previous studies in both typically and atypically developing children have shown that approximate number system (ANS) abilities predict formal mathematical knowledge later on in life. The current study investigated whether playing specially designed training games that targets the ANS system using non-symbolic stimuli only would improve preschool children’s ANS abilities. Thirty-eight preschool children were randomly allocated to either the training or control group. For five weeks, 20 preschoolers (9 girls) in the training group played daily games for ten minutes that included guessing and comparing numerosities whereas 18 control children (6 girls) were involved in interactive picture book reading sessions. Children’s ANS abilities were assessed using a computerized task, before and after the training programme. An ANCOVA with post-training ANS scores as dependent variable and pre-training scores as a covariate showed that the children in the training group had higher ANS abilities after the training, in contrast to children in the control group $\left(p=.012, \eta^{2}{ }_{p}=\right.$ .171). This study provides evidence that ANS abilities can be improved in preschool children through a daily training programme that targets the ANS specifically. These findings provide support for further training programmes for preschool children who show mathematical difficulties early on in life.
\end{abstract}

Keywords: preschoolers, mathematics, Approximate Number Sense, training 
Improving Approximate Number Sense Abilities in Preschoolers: PLUS Games Recently the development of mathematical abilities in young children has received increased attention, especially because mathematical abilities have been found to predict financial and educational success later on in life (Crawford \& Cribb, 2013; Geary, Hoard, Nugent, \& Bailey, 2013). Thus, a number of studies have looked into the mechanical underpinnings of mathematical abilities with the aim to develop more efficient teaching programmes. A number of programmes currently seek to target the emergent mathematical skills in preschool children (Cotter, 2000; Greenes, Ginsburg, \& Balfanz, 2004; Griffin, 2004; Passolunghi \& Costa, 2016; Sarama \& Clements, 2004; Sella, Tressoldi, Lucangeli, \& Zorzi, 2016; Siegler \& Ramani, 2008; Starkey, Klein, \& Wakeley, 2004; Whyte \& Bull, 2008; Wilson, Dehaene, Dubois \& Fayol, 2009; Young-Loveridge, 2004). These training programmes include different activities designed to promote a range of symbolic-related skills, including counting, recognizing and writing numbers, one-to-one correspondence, comparisons of symbolic numerals, change operations, and understanding numbers.

In addition to these symbolic-related number capacities, our approximate number system (ANS) ability allows us to quickly estimate quantities without the use of symbols or language. So far, only a few studies have examined methods to improve ANS abilities (Dewind \& Brannon, 2012; Hyde, Khanum, \& Spelke, 2014; Park \& Brannon, 2013). These studies show that it is possible to improve ANS abilities for adults and school-age children. However, it is currently unclear whether earlier intervention programmes that target the ANS specifically would be effective in preschool children. As it is possible that ANS improvements observed in adults and school-aged children are mediated by symbolic knowledge (Lyons, Price, Vaessen, Blomert, \& Ansari, 2014; Nys, Ventura, Fernandes, Querido, \& Leybaert, 2013), it is 
necessary to examine whether ANS abilities can be improved through training programmes in young children who have had no formal education yet.

\section{The Approximate Number System}

Children's understanding of numerosities is helped by a nonverbal innate capacity for processing numerosities (Butterworth, 2005; Piazza, 2010). Evidence from studies examining number abilities in infants and animals suggest that there are two early pre-verbal systems for numerical quantification (Feigenson, Dehaene, \& Spelke, 2004; Xu, 2003). One of the systems is used to represent small numerosities and it has been argued that this system is very precise and is akin to a memory system or Object Tracking System (OTS). This system has been linked to subitizing abilities that allow very quick and accurate estimation of small sets of either thee or four items (Feigenson et al., 2004). In contrast, the ANS is a noisy, imprecise, non-verbal system that allows fast discrimination of large numerosities without counting or the use of numerical symbols. This system relies upon the ratios between stimuli that are presented, known as Weber's fraction (w). Over development, children's ANS system increases in precision and children become better at discriminating between smaller ratios (Feigenson, Carey, \& Hauser, 2002; Halberda, \& Feigenson, 2008).

One dominant theory is that ANS abilities serve as a foundation for symbolic mathematics. Studies in both typical development and developmental disorders have shown that the ANS is predictive for number ability outcomes later on in life and that inter-individual differences in $w$ can be explained by differences in ANS acuity (Halberda, Mazzocco, \& Feigenson, 2008; Libertus, Feigenson, \& Halberda, 2011; Mazzocco, Feigenson, \& Halberda, 2011a, b; Van Herwegen, Ansari, Xu, \& Karmiloff-Smith, 2008). Yet, other studies have failed to find a relationship between mathematical abilities and ANS acuity (see De Smedt, Noël, Gilmore, \& Ansari 2013 
for a discussion). Moreover, recent evidence has shown that the relationship between ANS and mathematical abilities might be affected by informal and formal education (Lyons et al., 2014; Nys et al., 2013) but others have disputed the effect of schooling on non-symbolic magnitude processing (Zebian \& Ansari, 2012).

\section{ANS Training}

Information about the malleability of ANS abilities would be the first step to understand how ANS contributes to math skills. So far, only a few studies have examined the possibility to specifically improve ANS abilities, i.e., the ability to quickly estimate where is more, and these have been mainly focused on schoolchildren and adults. A number of studies have shown that training of non-symbolic comparison tasks or quantity comparison tasks in which participants had to add or subtract amounts of dots improve symbolic number abilities (Hyde, Khanum, \& Spelke, 2014; Park \& Brannon, 2013, 2014). For example, Park and Brannon (2013) trained adults over 10 sessions on an approximation task in which participants were shown addition and subtraction sums of visually presented dot areas varying from 9 to 36 dots. The participants were asked whether the outcome was larger or smaller than a third visual array displayed or matched a third display. The results showed that participants performed better on the approximation task after 10 training sessions and that this in turn had a positive impact on their ability to solve multi-digit addition and subtraction problems. A recent study by Hyde and colleagues (2014) showed that 6year-olds who received training over two sessions on non-symbolic approximate numerical addition tasks were faster to complete exact symbolic addition test problems. Still, these studies have mainly included participants who already have some formal mathematical training and thus it is unclear whether previous symbolic mathematical knowledge drives participants’ improvement in ANS accuracy. 
One training programme that is centred on strengthening the connection between symbolic number representation and non-verbal numerosity representation in preschool children is the "Number Race". The results of this training programme have been mixed in that primary school children with mathematical learning difficulties showed improved ANS acuity and subtraction skills after five weeks of training (Wilson, Revkin, Cohen, Cohen, \& Dehaene, 2006), whereas preschool children from low socioeconomic backgrounds only improved for symbolic number comparisons and not for ANS acuity (Wilson, Dehaene, Dubois, \& Fayol, 2009). Thus, there currently is no firm evidence that ANS acuity can be improved in preschoolers. In addition, the “Number Race” game includes symbolic stimuli as well as non-symbolic stimuli. Therefore, intervention studies using the Number Race cannot provide further insight into the cognitive mechanisms that drive the relationship between ANS acuity and number development as either symbolic, non-symbolic or both types of stimuli together might drive the enhancement.

\section{The Present Study}

The current study explored whether ANS acuity can be improved in preschoolers who have not received any formal mathematical education yet. Specifically, we investigated whether typically developing 2- to 5-year-old children who played specially designed comparison and estimation games, called PLUS, that include only non-symbolic materials would show improved ANS abilities, in comparison to an active control group. It was predicted that if the PLUS games improved ANS abilities, children in the training group should have better ANS scores after the training than the control group.

\section{Method}

\section{Participants}


Originally 52 children between the ages of 2 years and 5 months and 4 years and 9 months were recruited from five private nurseries within the Royal Borough Kingston in the Southeast of the UK. Fourteen children did not complete the programme either due to illness, the fact they went on holiday for a number of weeks, or they had left the nursery by the time post-training assessment took place, leaving 38 children for whom data could be collected both at pre-and post-training (See Flow chart). The children who did not complete the study did not differ from those in the final sample in terms of SES, pre-training abilities, age, or general intelligence (all $p$ 's $>0.05)$.

Mothers' highest level of education was used as a proxy to establish the socioeconomic status (SES) of the sample, as parental education is considered to be one of the most stable aspects of SES (Sirin, 2005). In addition, the South East of the UK is seen as an affluent area in that it ranks 8th out of 149 in the Child Wellbeing Index (Index of Multiple Deprivation, 2015) which suggests that it has the 8th lowest distribution of income deprivation within the UK. In addition, all parents paid privately for their child's nursery placement. Therefore, it can be assumed that the majority of the participants in the study did not include any children from low SES backgrounds. Four per cent of mothers did not have any qualifications when leaving secondary school, $19 \%$ were educated to A’ levels (high school diploma), 11\% had vocational equivalents, $62 \%$ of mothers held a degree and $4 \%$ a $\mathrm{PhD}$. In addition, all families spoke English at home and none of the children had a diagnosis for a developmental disorder or had problems with vision or hearing.

This study was approved by the Ethics Committee for Arts and Social Sciences at $\mathrm{xxxxx}, \mathrm{xx}$. Parental written consent was obtained for all children as well as children's verbal assent before the start of the study. 


\section{Materials}

British Ability Scales (BAS3). The BAS3 is a standardised assessment battery for children aged 3 to 17 years old and measures verbal, non-verbal and general reasoning abilities. We carried out 6 core scales of the Early Years cognitive battery which were used to derive a General Cognitive Ability (GCA) standard score (BAS3; Eliot \& Smith, 2011) which has a mean of 100 and a standard deviation of 15 points on either side. The technical manual reports an average test-retest reliability coefficient for the composite GCA scale of .93 (range= .91-.94) for the early year age range.

ANS abilities. Children's ANS abilities were assessed pre- and post-training using the ANS test. This computerised test was based upon the materials used in Halberda and Feigenson (2008). However, in contrast to the original test by Halberda and Feigenson (2008), children responded by touching a screen in order to reduce eye-hand coordination difficulties. Children received motivational feedback for both practice and test items to encourage children to stay on task. For a correct answer, a green smiley face appeared with a cheering sound. For incorrect responses, a red sad face appeared with the sound “oh”. Following four practice trials, 60 test items trials were presented in random order using the software program E-prime 2.0 software (Psychology Software Tools, Pittsburgh, PA). The trails included two pictures displaying different ratios of 1-16 dots (see Table 1). Each ratio was presented six times using six different overall contour lengths and lay-outs (2.9981, 4.1012, 5.0912, 5.9397, 6.2225, $6.7034 \mathrm{~cm}$ total diameter length). Children were asked to touch the picture that showed "more". The number of correct responses was recorded. There was no time restriction to answer but children were encouraged throughout the game 
to answer as fast as they could. All children scored at least 3 out of the 4 practice trials correctly (See Table 1).

The ANS test was carried out within one week before and after the training by a different researcher than the one who provided the training in order to ensure that researchers were blind to the group the child belonged to.

The ANS test included both small quantities that are within the subitizing range (1 to 3 dots) and thus the number of dots could have been exactly estimated compared to those sets that have larger quantities and which could only be approximately estimated. Evidence from research in neurodevelopmental disorders (Karmiloff-Smith et al., 2012; Van Herwegen, 2008; Van Herwegen \& Karmiloff-Smith, 2015) has suggested that large quantity discrimination but not small quantity discrimination taps into ANS abilities. There is currently still debate as to what quantities (i.e. 3 or 4 items) can be processed by a "small” or object-file system and which ones are processed by the ANS that is responsible for the estimation of larger amounts. In the final ANS scores we therefore only included the answers for those ratios that fall clearly outside the subitizing range (i.e., ratio 1:2 (8 versus 16 dots), ratio 2:3 (8 versus 12 dots), ratio 3:4 (6 versus 8 dots), ratio 4:5 (8 versus 10 dots), ratio 5:6 (5 versus 6 and 10 vs 12 dots) $)^{1}$. Cronbach’s alpha for the final included items was .74.

\section{Procedure}

Within each nursery, the participating children were randomly allocated to either the training or control group with an allocation ratio of 1:1. Random allocation happened through the use of an online random number generator. Both types of intervention programmes included physical games and both groups continued to take

1 This also meant that the quantities included in the analyses were similar to Hyde et al. (2014) who included quantity arrays between 4 and 15 dots for the ANS task. 
part in their day-to-day activities in the pre-school settings (i.e., the training programmes described below did not replace the usual activities).

PLUS Training programme. Children in the training group followed the Preschool number learning scheme (PLUS) and it was aimed that children should play PLUS games for 10 minutes each day for a time period of five weeks, either on a one-to-one basis with a trained researcher or in small groups of two children and a researcher. However, due to the fact that preschool children are not obliged in the UK to attend preschool every day, not all children received training on a daily basis.

The PLUS games include two types of games, each type matching a function of the ANS system: four approximation or estimation games to and four games in which children were asked to compare or differentiate between different amounts of various ratios. The tasks were adapted from games familiar to preschoolers and the stimuli of the games related to a variety of senses, including touch, sounds, and visual stimuli, as theoretically the ANS has been argued to be an a-modal system (Feigenson et al., 2004). For those games that included cards, factors that are confound with number (such as contour length and total area) were controlled for by including objects of different sizes. A description of each game can be found in the Appendix 1.

During each session, the child played one guessing and one comparison game. In all games the children were prevented from counting by not providing children the time to count (i.e., by asking the children to compete with each other and completing the game as quickly as they could) or by showing the stimuli only for a very short time (about 1 second). All of the games started with large ratios (i.e., 1/2) or clear differences between the number of items presented to explain the aim of the games and the ratios became harder (e.g., 6 vs 8) and the number presented larger as the weeks of training progressed to train the child's ANS abilities. 
For all games, children received feedback about whether or not they had chosen the correct amount. For the guessing games, this feedback never included the actual number but a discussion about the size of the numbers. For example, if the child replied 16 and another child said 5, the researcher would discuss that 16 is much larger than 5. In addition, the games were semi-randomly rotated on a daily basis between children so that on each day they played a different guessing and a different comparison game to the day before. However, all children played the same types of games for the same amount of time across all of the sessions.

Control Training programme. Children in the control group took part in interactive or shared picture book reading with a researcher, either in a one-on-one session between child and researcher or in small groups of two children with a researcher for 10 minutes per day for five weeks. The control group was included to ensure that progress in the training group was not caused by development in general or any number games the children played in the nursery other than the PLUS games.

Five full-time post-graduate researchers (one per nursery), who were full-time students on a Master of Science in Child Psychology and who had experience with standardised assessments as well as working with preschool children, were trained over five sessions of two hours five weeks prior to the intervention programmes by the first author to implement both of the training programmes with children in the control and experimental group from one nursery. The training included a training manual, role-play sessions, as well as practice with feedback. The researchers were not informed about the aim of the study, except that the training programmes would be beneficial to preschoolers' general abilities. The first author visited each preschool setting twice during the 5-week training programme to ensure treatment fidelity 
through qualitative observations of the sessions, which focused on the difficulty level of the games, type and amount of feedback provided by the researcher. For any differences from the training manual observed, researchers received verbal feedback and were instructed to consult the training manual. However, no serious treatment fidelity issues were observed. In addition, researchers were provided with a randomised order of the types of games to play during each session. The researchers noted down the number of sessions for each child.

\section{Results}

There was no difference between the two experimental groups for chronological age; $t(36)=-.32, p=.753$. Although GCA scores from BAS ranged from "below average" to "very high" (83-141), there was no difference between the two groups; $t(34)=-1.01, p=.320$, Cohen's $d=.09$. As shown in Table 2 , the two experimental groups did not differ for the amount of 1 -on-1 sessions received; $t(36)=$ $1.57, p=.125$, Cohen's $d=.33$. There was no difference for the number of boys and girls included in each group; $\chi^{2}(1, N=38)=.40, p=.463$, Cohen’s $d=.34$. A 5 by 2 Chi-square analysis showed no differences for SES between the groups: $\chi^{2}(5, N=38)$ $=4.714, p=.452$. Therefore, these factors were not further included as covariates in the analyses.

Both the pre- and post-training ANS scores were normally distributed and thus parametric tests were carried out. In addition, both groups performed above chance level (scores above 20/36). An ANOVA showed no differences between the two groups for pre-training scores ANS scores; $F(1,37)=1.136, p=.294, \eta^{2}=.031$. The children in the PLUS training programme obtained an average score of 21.65 (SD $=5.55$ ) and those in the control programme had a mean pre-training score of 23.61 
$(\mathrm{SD}=5.79)$. An ANCOVA $^{2}$ with post-training scores as the dependent variable and pre-training scores as a covariate showed a significant effect for group; $F(1,37)=$ 5.57, $p=.024, \eta_{\mathrm{p}}^{2}=.141$ and for pre-training scores; $F(1,37)=56.935,<.001, \eta_{\mathrm{p}}^{2}=$ .626. As can be seen in Table 3, only the training group increased on large quantity discrimination post-training and adjusted means show that they have higher ANS scores at post-testing compared to the control group.

\section{Discussion}

The current study investigated whether playing PLUS games that target the ANS system using non-symbolic stimuli only would improve preschool children’s ANS abilities, in contrast to a group of preschoolers who were involved in interactive book reading sessions for five weeks. As expected, our findings showed that the children in the PLUS training group significantly increased their ANS skills compared to the active control group. The PLUS games target two main functions of the ANS: comparison of large numerosities as well as estimation. The researcher manipulated the ratios of the amount of objects presented starting with easy ratios and small amount within the subitizing range to explain the games and then moved on to large numerosities and more difficult ratios during the training, based upon the child's abilities and correct responses to easier trials. Children started with numerosities that were far apart but this distance became smaller as they progressed through the programme. In addition, children received varying ratios as they progressed through the training programme and this resembled the progression observed in previous

2 We chose to complete an ANCOVA analysis as repeated measures analysis examines the effect of the treatment on both the pre-test and post-test scores whereas for the current intervention programmes only an intervention effect on the post-test scores was expected. Thus, an ANCOVA rather than a repeated measures analysis was chosen to avoid a very conservative $F$ value for the treatment (see Huck and McLean, 1975 for a discussion). 
studies, with infants being able to discriminate between larger ratios and older children being able to discriminate between smaller and more difficult ratios (Feigenson et al., 2004). Therefore, the PLUS games target the distance effect as well as the size effect which resulted in a better post-training ANS acuity scores for all children in the training group.

\section{Implications for Research and Practice}

This encouraging result is consistent with previous studies of ANS training in adults and school-aged children (Hyde et al., 2014; Park \& Brannon, 2013, 2014). Moreover, Wilson and colleagues (2006) provided evidence that improving ANS abilities is possible in primary school children with a training programme (the "Number Race”) centered on strengthening the connection between symbolic number representation and non-verbal numerosity representations. The current results are in line with this previous study by Wilson and colleagues (2006) and provide evidence that ANS acuity can be improved in preschoolers using only non-symbolic stimuli. This finding is important for future studies that may want to further examine the underlying mechanisms of the relationship between ANS acuity and formal mathematical abilities by examining how this improvement in ANS acuity using nonsymbolic stimuli relates to symbolic mathematical knowledge in preschoolers.

Previous studies have also shown that the relationship between ANS precision and mathematical abilities is stronger in children who are at risk of developing mathematical difficulties (Mazzocco et al., 2011a). Therefore, future studies might want to target children who are at risk for mathematical difficulties, as they might show even stronger improvements for mathematical abilities following training using PLUS games.

\section{Limitations}


The current study used strict inclusion criteria and due to the nature of working with young preschool children in nurseries in the UK where attendance is not obligatory, the number of children included in the final sample was relatively small. However, the effect sizes were medium to large (Cohen, 1988) and the total number of children per group is similar to those in other training studies with preschoolers (Kroesbergen, van’t Noordende, \& Kolkman, 2014; Siegler \& Ramani, 2008; Whyte \& Bull, 2008). A second limitation regards the lack of information about the durability of any gains made by training. Recent studies have shown that homeenvironment plays an important role in preschool children's mathematical abilities (Benavides-Varela et al., 2016; Melhuish et al., 2008). The current study did not examine the role of the home environment on the effect of the training programmes and did not include any children from low SES backgrounds. Instead, the current study focused on whether ANS abilities could be improved in preschool children and not on the individual differences that may interact with such improvements. Further follow-up studies are needed, especially those with larger sample sizes, to examine whether beneficial effects of preschool training on ANS acuity are maintained over time, as well as how these effects are mediated by the number of training sessions, SES, gender differences, overall cognitive abilities as well as by treatment fidelity and implementation. Finally, the current study only recorded improvements on a classic ANS task in which children select the picture that shows a larger set of dots on the screen. However, previous studies have shown that the reliability of such tasks depends on a number of methodological issues, including the number of trials and the size and ratios of the dots shown (see Dewind \& Brannon, 2016 and Clayton, Gilmore, \& Inglis, 2015 for a discussion). Therefore, it is important that the results for the ANS task are backed-up by other measures as well as there is no data about the 
test-retest reliability of the ANS task in the current study. In addition, the increase on the ANS task is minimal and thus it is not known what the educational relevance is of this increase. Additional measures, such as number line data as well as performance on formal mathematical tasks would provide further insight into the validity and reliability of the current results.

\section{Conclusions}

Although more research in this area is required, the current study contributes to the understanding of mathematical learning and provides evidence that ANS abilities in preschool children can be improved through games that target the ANS directly using non-symbolic stimuli only. The successful results obtained may open the door for further ANS training programmes for children who show mathematical difficulties early on in life, which in turn may improve their numerical skills later in life. 


\section{References}

Adrien, J. E., Clemente, R. A., Villanueva, L., \& Rieffe, C. (2005). Parent-child picture-book reading, mothers' mental state language and children's theory of mind. Journal of Child Language, 32(3), 673-686.

doi:10.1017/S0305000905006963

Benavides-Varela, S., Butterworth, B., Burgio, F., Arcara, G., Lucangeli, D., \& Semenza, C. (2016). Numerical Activities and Information Learned at Home Link to the Exact Numeracy Skills in 5-6 Years-Old Children. Frontiers in Psychology, 7, 94. doi:10.3389/fpsyg.2016.00094

Bonny, J. W., \& Lourenco, S. F. (2013). The approximate number system and its relation to early math achievement: Evidence from the preschool years. Journal of Experimental Child Psychology, 114(3), 375-88.

doi:10.1016/j.jecp.2012.09.015

Butterworth, B. (2005). The development of arithmetical abilities. Journal of Child Psychology and Psychiatry, 46, 3-18. doi: 10.1111/j.1469-7610.2004.00374.x

Clayton, S., Gilmore, C. \& Inglis, M. (2015). Dot comparison stimuli are not all alike: The effect of different visual controls on ANS measurement. Acta Psychologica, 161, 177-184, doi. 10.1016/j.actpsy.2015.09.007

Cohen, J. (1988). Statistical power analysis for the behavioral sciences (2nd ed.). Hillsdale, NJ: Lawrence Erlbaum Associates.

Crawford, C. \& Cribb, J. (2013) Reading and maths skills at age 10 and earnings in later life: A brief analysis using the British cohort study. (Report No. 3). UK: Centre for Analysis of Youth Transitions.

Cotter, J. A. (2000). Using Language and Visualization to Teach Place Value. Teaching Children Mathematics, 7, 108-114. 
De Smedt, B., Noël, M. P., Gilmore, C., \& Ansari, D. (2013). How do symbolic and non-symbolic numerical magnitude processing skills relate to individual differences in children's mathematical skills? A review of evidence from brain and behavior. Trends in Neuroscience and Education, 2, 48-55. doi:10.1016/j.tine.2013.06.001

Dewind, N. K. \& Brannon, E. M. (2012). Malleability of the approximate number system: effects of feedback and training. Frontiers in Human Neuroscience, 6, 1-10. doi:10.3389/fnhum.2012.00068

DeWind, N. K., \& Brannon, E. M. (2016). Significant Inter-Test Reliability across Approximate Number System Assessments. Frontiers in Psychology, 7, 310. doi:10.3389/fpsyg.2016.00310

Eliot, C. D. \& Smith, P. (2011). British Ability Scales (Third edition): BAS3. GL Assessment.

Feigenson, L., Carey, S., \& Hauser, M. (2002). The representations underlying infants’ choice of more: Object-files versus analog magnitudes. Psychological Science, 13, 150-156. doi:10.1111/1467-9280.00427

Feigenson, L., Dehaene, S., \& Spelke, E. S. (2004). Core systems of number. Trends in Cognitive Science, 8(7), 307-314. doi:10.1016/j.tics.2004.05.002

Fuhs, M. W., \& McNeil, N. M. (2013). ANS acuity and mathematics ability in preschoolers from low-income homes: contributions of inhibitory control. Developmental Science, 16(1), 136-148. doi:10.1111/desc.12013

Geary, D. C., Hoard, M. K., Nugent, L., \& Bailey, D. H. (2013). Adolescents” functional numeracy is predicted by their school entry number system knowledge. PLoS ONE, 8(1), e54651. doi:10.1371/journal.pone.0054651 
Gilmore, C. K., McCarthy, S. E., \& Spelke, E. S. (2010). Non-symbolic arithmetic abilities and mathematics achievement in the first year of formal schooling. Cognition, 115(3), 394-406. doi:10.1016/j.cognition.2010.02.002

Griffin, S. (2004). Building number sense with Number Worlds. Early Childhood Research Quarterly, 19, 173-180. doi:10.1016/j.ecresq.2004.01.012

Greenes, C., Ginsburg, H. P. \& Balfanz, R. (2004). Big Math for Little Kids. Early Childhood Research Quarterly, 19, 159-166. doi:10.1016/j.ecresq.2004.01.010

Halberda, J., \& Feigenson, L. (2008). Developmental change in the acuity of the “number sense”: The approximate number system in 3-, 4-, 5-, and 6-year-olds and adults. Developmental Psychology, 44(5), 1457-1465.

doi:10.1037/a0012682

Halberda, J., Mazzocco, M. M. M., \& Feigenson, L. (2008). Individual differences in non-verbal number acuity correlate with maths achievement. Nature, 455(7213), 665-668. doi:10.1038/nature07246

Holloway, I. D., \& Ansari, D. (2009). Mapping numerical magnitudes onto symbols: The numerical distance effect and individual differences in children’s mathematics achievement. Journal of Experimental Child Psychology, 103, 1729. doi:10.1016/j.jecp.2008.04.001

Hyde, C. D., Khanum, S., \& Spelke, E. S. (2014). Brief non-symbolic, approximate number practice enhances subsequent exact symbolic arithmetic in children. Cognition, 131, 92-107. doi:10.1016/j.cognition.2013.12.007

Karmiloff-Smith, A., D’Souza, D., Dekker, T., Van Herwegen, J., Xu, F., Rodic, M., \& Ansari, D. (2012). Genetic and environmental vulnerabilities: the importance of cross-syndrome comparisons. Proceedings of the National Academy of Sciences U.S.A., 190(2), 17261-17265. doi:10.1073/pnas.1121087109 
Kroesbergen, E. H., van’t Noordende, J. E., \& Kolkman, M. E. (2014). Training working memory in kindergarten children: Effects on working memory and early numeracy. Child Neuropsychology, 20, 23-37. doi:10.1080/09297049.2012.736483

Libertus, M. E., Feigenson, L., \& Halberda, J. (2011). Preschool acuity of the approximate number system correlates with school math ability. Developmental Science, 14(6), 1292-1300. doi:10.1111/j.1467-7687.2011.01080.x

Libertus, M. E., Odic, D., \& Halberda, J. (2012). Intuitive sense of number correlates with math scores on college-entrance examination. Acta Psychologica, 141(3), 373-379. doi:10.1016/j.actpsy.2012.09.009

Lyons, I. M., Price, G. R., Vaessen, A., Blomert, L. \& Ansari, D (2014). Numerical predictors of arithmetic success in grades 1-6. Developmental Science, 17(5), 714-726. doi:10.1111/desc.12152

Mazzocco, M. M. M., Feigenson, L., \& Halberda, J. (2011a). Impaired acuity of the approximate number system underlies mathematical learning disability (Dyscalculia). Child Development, 82(4), 1224-1237. doi:10.1111/j.14678624.2011.01608.x

Mazzocco, M. M. M., Feigenson, L., \& Halberda, J. (2011b). Preschoolers’ precision of the approximate number system predicts later school mathematics performance. PLoS One, 6(9):e23749. doi:10.1371/journal.pone.0023749

Melhuish, E.C., Sylva, K., Sammons, P., Siraj-Blatchford, I., Taggart, B., Phan, M.B., \& Malin, A. (2008). The early years. Preschool influences on mathematics achievement. Science, 321(5893),1161-1162. doi: 10.1126/science.1158808

Nys, J., Ventura, P., Fernandes, T., Querido, L., \& Leybaert, J. (2013). Does math education modify the approximate number system? A comparison of schooled 
and unschooled adults. Trends in Neuroscience and Education, 2, 13-22. doi:10.1016/j.tine.2013.01.001

Park, J. \& Brannon, E. M. (2013). Training the approximate number system improves math proficiency. Psychological Science, 24(10), 2013-2019. doi:10.1177/0956797613482944

Park, J., \& Brannon, E. M. (2014). Improving arithmetic performance with number sense training: An investigation of underlying mechanism. Cognition, 133, 188200. doi:10.1016/j.cognition.2014.06.011

Passolunghi, M. C., \& Costa, H. M. (2016). Working memory and early numeracy training in preschool children. Child Neuropsychology, 22(1), 81-98. doi:10.1080/09297049.2014.971726

Piazza, M. (2010). Neurocognitive start-up tools for symbolic number representations. Trends in Cognitive Sciences, 14(12), 542-551. doi:10.1016/j.tics.2010.09.008

Rasmussen, C., \& Bisanz, J. (2005). Representation and working memory in early arithmetic. Journal of Experimental Child Psychology, 91, 137-157. doi:10.1016/j.jecp.2005.01.004

Sarama, J. \& Clements, D. H. (2004 ). Building Blocks for early childhood mathematics. Early Childhood Research Quarterly, 19, 181-189. doi:10.1016/j.ecresq.2004.01.014

Sasanguie, D., De Smedt, B., Defever, E., \& Reynvoet, B. (2012). Association between basic numerical abilities and mathematics achievement. British Journal of Developmental Psychology, 30(2), 344-357. doi:10.1111/j.2044835X.2011.02048.x

Sella, F., Tressoldi, P., Lucangeli, D., \& Zorzi, M. (2016). Training numerical skills with the adaptive videogame "The Number Race”: A randomized controlled 
trial on preschoolers. Trends in Neuroscience and Education, 5, 20-29. doi:10.1016/j.tine.2016.02.002

Siegler, R. S., \& Ramani, G. B. (2008). Playing linear numerical board games promotes low-income children's numerical development. Developmental Science, 11(5), 655-661. doi: 10.1111/j.1467-7687.2008.00714.x

Sirin, S. R. (2005). Socioeconomic Status and Academic Achievement: A MetaAnalytic Review of Research. Review of Educational Research, 75(3), 417-453. doi:10.3102/00346543075003417

Starkey, P., Klein, A., \& Wakeley, A. (2004). Enhancing young children’s mathematical knowledge through a pre-kindergarten mathematics intervention. Early Childhood Research Quarterly, 19, 99-120. doi:10.1016/j.ecresq.2004.01.002

Soltész, F., Szücs, D., \& Szücs, L. (2010). Relationships between magnitude representation, counting and memory in 4-to 7-year-old children: A developmental study. Behavioral and Brain Functions, 6, 1-14. doi:10.1186/1744-9081-6-13

Stigler, S. M (1997). Regression toward the mean, historically considered. Statistical Methods in Medical Research, 6(2), 103-114. doi:10.1191/09622809767636143

Vanbinst, K., Glesquière, P., \& De Smedth, B. (2012). Numerical magnitude representations and individual differences in children's arithmetic strategy use. Mind, Brain, and Education, 6, 129-136. doi:10.1111/j.1751228X.2012.01148.x

Van Herwegen, J., Ansari, D., Xu, F., \& Karmiloff-Smith, A. (2008). Small and large number processing in infants and toddlers with Williams syndrome. Developmental Science, 11, 637-643. doi:10.1111/j.1467-7687.2008.00711.x 
Van Herwegen, J. \& Karmiloff-Smith, A (2015). Genetic developmental disorders and numerical competence across the lifespan. In R. Cohen Kadosh \& A. Dowker (Eds.), Oxford Handbook of Numerical Cognition (pp. 721-732). Oxford: Oxford University Press. doi:10.1093/oxfordhb/9780199642342.013.031

Wasik, B. A. \& Bond, M. A. (2001). Beyond the pages of a book: Interactive book reading and language development in preschool classrooms. Journal of Educational Psychology, 93(2), 243-250. doi:10.1037//0022-0663.93.2.243

Whyte, J. C., \& Bull, R. (2008). Number games, magnitude representation, and basic number skills in preschoolers. Developmental Psychology, 44(2), 588-596. doi:10.1037/0012-1649.44.2.588

Wilson, A. J., Dehaene, S., Dubois, O., \& Fayol, M. (2009). Effects of an adaptive game intervention on accessing number sense in low-socioeconomic-status kindergarten children. Mind, Brain, and Education, 3, 224-234. doi:10.1111/j.1751-228X.2009.01075.x

Wilson, A. J., Revkin, S. K., Cohen, D., Cohen, L., \& Dehaene, S. (2006). An open trial assessment of" The Number Race", an adaptive computer game for remediation of dyscalculia. Behavioral and Brain Functions, 2:20. doi:10.1186/1744-9081-2-20

Young-Loveridge, J. M. (2004). Effects on early numeracy of a program using number books and games. Early Childhood Research Quarterly, 19, 82-98. doi:10.1016/j.ecresq.2004.01.001

Xu, F. (2003). Numerosity discrimination in infants: Evidence for two systems of representations. Cognition, 89, B15-B25. doi:10.1016/S0010-0277(03)00050-7 
RUNNING HEAD: IMPROVING ANS IN PRESCHOOLERS 
Table 1

Overview of ratios and number of dots in ANS game. For each ratio 6 small and 6 large numbers were presented. Those highlighted in bold were included in the final analyses

\begin{tabular}{llllll}
\hline Ratios & $1: 2$ & $2: 3$ & $3: 4$ & $4: 5$ & $5: 6$ \\
\hline Small number & 1 vs 2 dots & 2 vs 3 dots & 3 vs 4 dots & 4 vs 5 dots & 5 vs $\mathbf{6}$ dots \\
Large number & $\mathbf{8}$ vs $\mathbf{1 6}$ dots & $\mathbf{8}$ vs $\mathbf{1 2}$ dots & $\mathbf{6}$ vs $\mathbf{8}$ dots & $\mathbf{8}$ vs $\mathbf{1 0}$ dots & $\mathbf{1 0}$ vs $\mathbf{1 2}$ dots \\
\hline
\end{tabular}


Table 2

Descriptive statistics for the training and control group: Chronological Age (CA),

General Cognitive Ability (GCA) scores and amount of training sessions

\begin{tabular}{llllll}
\hline & \multicolumn{2}{c}{ Training group } & & \multicolumn{2}{c}{ Control group } \\
& $\mathrm{N}=20$ (9 Female) & & \multicolumn{2}{c}{$\mathrm{N}=18$ (6 Female) } \\
\cline { 2 - 3 } \cline { 5 - 6 } & Mean & (SD) & & Mean & (SD) \\
\hline CA in months & 45.20 & $(7.20)$ & & 45.80 & $(6.06)$ \\
GCA scores & 103.89 & $(12.60)$ & & 107.88 & $(10.89)$ \\
Training sessions & 16.70 & $(5.20)$ & & 14.39 & $(3.63)$ \\
\hline
\end{tabular}


Table 3

Overview of ANS scores per group both pre- and post-training (maximum score is 36).

\begin{tabular}{lllllll}
\hline & \multicolumn{2}{c}{ ANS Pre-training } & \multicolumn{2}{l}{$\begin{array}{l}\text { ANS Post - } \\
\text { training }\end{array}$} & \multicolumn{2}{l}{$\begin{array}{l}\text { Adjusted ANS post- } \\
\text { training }\end{array}$} \\
& Mean & (SD) & Mean & (SD) & Mean & (SE) \\
\hline $\begin{array}{l}\text { Training } \\
\text { group }\end{array}$ & 21.65 & $(5.55)$ & 24.25 & $(5.93)$ & 24.91 & $(0.77)$ \\
Control & 23.61 & $(5.79)$ & 24.72 & $(4.32)$ & 23.99 & $(0.81)$ \\
group & & & & & & \\
\hline
\end{tabular}


Figure 1: Flow diagram of the participants included in the training

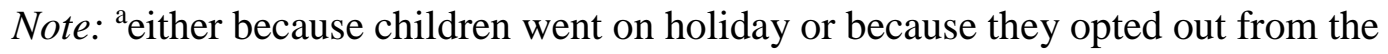
games

Appendix 1

Guessing games:

1. Guessing game: In this game children were asked questions about how many items they thought were presented. For example, how many sweets are in this box, how many keys on the keypad, how many leaves on this tree, how many people are in this room etc. Regardless of the answer children received a sticker for their guess. If children did not guess the researcher guessed, i.e. "I think there are more/less than...” or the researcher discussed the number said by the child by saying “yes, 50 is a lot”. This game promotes guessing and allows children to learn new number words that are introduced by the researcher via the feedback that is provided. Again children were asked to answer as fast as they could.

2. In a line: children were presented with a target card on the table with 4 to 16 coloured objects of different sizes on them in a random order. Next, they were shown a new card and asked whether the new card had more or less objects on it and to put the card either on the left (less items) or on the right (more items) of the target card. Children were asked to respond as fast as they could and the card with the new objects was only presented for a very short time to prevent counting strategies.

3. Grab and guess: in this game children were asked to grab some uncooked pasta from a box in turns. The box contained different sizes and shapes of pasta. After the child had grabbed some pasta, the researcher would grab some (carefully controlling that the amount would fall within ANS range and was 
close or different from the child's) and both put the pasta in front of them, then the child was asked who had more or who had less pasta. Again, children were asked to respond as fast as possible.

4. In the sock: In this game the researcher hid two different amounts of different sized beads in two different socks. Each child was then asked to feel both of the socks with each hand and to guess which sock contained either more or fewer beads. The socks were only presented for a short time to prevent counting.

\section{Comparison games:}

5. Play that number: in this game the child and experiment sat back to back from each other so that they could not see each other. The experimenter played a number of sounds of different loudness and speed on an instrument and then the child was asked to play a similar amount of sounds on a different instrument.

6. Dominoes: in this game children used special cards that displayed a scattered number of dots on the left and right side of the card. The amount of dots as well as the ratio between the number of dots on the left and right differed from card to card. Children were asked to identify which side of the card contained more dots and to match the correct side (large or small number) of their card with the card presented by the researcher on the table. So a child could have a card with 5 dots on left and 10 dots on right and the researcher one with 8 on right and 12 dots on the left. In this case the side with 10 dots would match the side with 12 dots as these sides both have more.

7. Matching game: using cards with 4 to 16 coloured objects of different sizes on them, children were asked to sort the card in their hand to cards presented on 
the table, putting large amounts of objects with large amounts and small amounts of objects with small. Again the researcher manipulated the ratios of the amount of objects presented starting with easy ratios and then increasing the amount of objects as well as more difficult ratios as the weeks progressed. Again children were asked to perform this task as quickly as possible and the experimenter showed the card to be sorted in the pile only very briefly.

8. Action game: in this game the experimenter performed a number of actions (e.g., clapped her hands a lot or only a few times) and the child was asked to repeat the number of time the action was performed. Actions were carried out very quickly to prevent counting. As with all games the researcher manipulated the amount of actions presented starting with smaller numbers (4 claps) and then increasing the amount as the weeks progressed. 